\title{
Microsatellite abnormalities and somatic down-regulation of mismatch repair characterize nodular-trabecular muscle-invasive urothelial carcinoma of the bladder
}

\author{
J Rubio, $^{1}$ A Blanes, ${ }^{1} \mathrm{~J} \mathrm{~J} \mathrm{Sanchez-Carrillo}^{1}$ \& S J Diaz-Cano ${ }^{1,2}$ \\ Departments of Pathology, ${ }^{1}$ University Hospital of Malaga, Malaga, Spain and ${ }^{2}$ King's College Hospital and King's College \\ London School of Medicine, London, UK
}

Date of submission 12 October 2006

Accepted for publication 20 February 2007

Rubio J, Blanes A, Sanchez-Carrillo J J \& Diaz-Cano S J

(2007) Histopathology 51, 458-467

\section{Microsatellite abnormalities and somatic down-regulation of mismatch repair characterize nodular-trabecular muscle-invasive urothelial carcinoma of the bladder}

Aims: To correlate histological infiltration patterns with genetic and mismatch repair (MMR) profiles in muscle-invasive bladder urothelial carcinomas (UroC). Methods and results: Infiltration patterns were assessed in the deep compartment of muscle-invasive UroC (nodular-trabecular, 45 cases; infiltrative, 27 cases). Tumour compartment (superficial and deep to muscularis mucosa) analysis included: microsatellite pattern of TP53, RB1, WT1 and NF1 by polymerase chain reaction/denaturing gradient gel electrophoresis; mitotic, Ki67, in situ end labelling (ISEL) indices and DNA ploidy. MMR was assessed by MLH1 and MSH2 sequencing and immunohistochemistry in UroC with two or more abnormal microsatellite loci. Statistical differences were tested using ANOVA and Fisher's exact tests. Infiltrative UroC showed lower Ki67 index
$14.94 \pm 4.28$, ISEL index $14.1 \pm 10.0$ and shorter median survival (20 months) than nodular-trabecular UroC (Ki67 index $20.65 \pm 4.94$, ISEL $20.2 \pm 22.7$, 37-month survival, respectively). The genetic profile was significantly different for RB1 $(P=0.0003)$ and NF1 ( $P=0.0023)$ only, being more frequently abnormal in nodular-trabecular UroC. A significant decrease in MLH1 or MSH2 protein expression with no gene mutations was identified in UroC with microsatellite abnormalities and a nodular-trabecular growth pattern.

Conclusions: Somatic down-regulation of MMR proteins in nodular-trabecular muscle-invasive UroC results in $\mathrm{RB} 1$ /NF1 microsatellite abnormalities, correlating with higher cellular turnover and longer survival.

Keywords: bladder, infiltration pattern, kinetic, microsatellite, prognosis, tumour suppressor gene, urothelial carcinoma

Abbreviations: BSA, bovine serum albumin; CIS, carcinoma in situ; HPF, high-power field; ISEL, in situ end labelling; LGUD, low-grade urothelial dysplasia; LOH, loss of heterozygosity; MF, mitotic figure; MMR, mismatch repair; NF1, neurofibromatosis 1; RB1, retinoblastoma; ROH, retention of heterozygosity; SNP, single nucleotide polymorphism; TP53, tumour protein p53; TSG, tumour suppressor gene; UroC, urothelial carcinoma; WT1, Wilm's tumour 1

\section{Introduction}

The invasive capacity of tumours partially determines the infiltration pattern and correlates with

Address for correspondence: Salvador J Diaz-Cano, MD, PhD, FRCPath, King's College Hospital, Department of Histopathology, Denmark Hill, London SE5 9RS, UK.

e-mail: salvador.diaz-cano@kcl.ac.uk tumour prognosis, which, for bladder urothelial carcinomas (UroC), mainly depends on the distinction between superficial and invasive. These patterns correlate with tumour grade and stage, nuclear DNA content and proliferation in various groups of UroC, ${ }^{1,2}$ but rarely in muscle-invasive UroC. Pathological $\mathrm{T}$ stage and lymph node status remain the most powerful predictors of progression in 
muscle-invasive UroC. In this group of patients, an infiltrative growth pattern may be associated with a more dismal prognosis, ${ }^{3}$ the biological reason for which remains unknown.

Substaging of pT1 UroC has improved the prediction of progression: ${ }^{4,5}$ tumours extending beyond the muscularis mucosa behave like muscle-invasive UroC, especially those high-grade UroC expressing TP53 and revealing associated carcinoma in situ. ${ }^{4-6}$ The level of muscularis mucosa has also been useful in assessing topographical histological and molecular heterogeneity in bladder UroC. ${ }^{7,8}$ This has resulted in distinctive microsatellite and clonal profiles leading to topographical segregation of proliferative and invasive tumour cells. $^{9-13}$ Therefore, topographical analysis of genetic and kinetic features will result in a better understanding of the molecular evolution of neoplasms. ${ }^{8}$

Genetic and kinetic profiles by topographical compartments have not been analysed in muscle-invasive UroC with respect to their patterns of infiltration (nodular-trabecular versus infiltrative). Th aim of this study was to analyse tumour suppressor gene (TSG) microsatellite patterns, mismatch repair (MMR) profiles, proliferation and apoptosis in muscle-invasive UroC using microdissected samples from the superficial and deep compartments to assess TSGs controlling $\mathrm{G}_{1}-\mathrm{S}$ transition (TP53, RB1), RAS pathway (NF1) and development (WT1). Tumours were stratified according to their deep compartment infiltration pattern (nodular-trabecular versus infiltrative) and data were correlated with cancer-specific survival.

\section{Materials and methods}

\section{CASE SELECTION AND SAMPLING}

Initial biopsy specimens of all muscle-invasive (pT2a/b only) lymph node-negative (pN1) UroC of the urinary bladder treated with cystectomy and lymphadenectomy only (72 cases) from three reference hospitals (1990-1992, median follow-up 60 months) were reviewed; all cases had properly preserved archival material for both tumour and control tissues (see below).

Topographical compartments were defined as superficial and deep to the muscularis mucosa, ${ }^{7,14}$ a limit that has been demonstrated to be prognostically useful in high-grade pT1 UroC. ${ }^{5}$ This protocol was approved by the Hospital Research Board and Ethics Committee and complied with their requirements.
TUMOUR INFILTRATION PATTERN, GRADING AND MITOTIC FIGURE COUNTING

The pattern of infiltration was evaluated in deep compartments, classifying the tumour by the predominant pattern $(>50 \%)$ of nodular-trabecular or infiltrative (Figure 1). Histological grading evaluated architectural features, nuclear grade and mitotic figure (MF) counting. ${ }^{2}$ MFs were screened in 50 high-power fields (HPF) per compartment $\left(7.140 \mathrm{~mm}^{2}\right)$ or the whole tumour if smaller (three superficial and six deep compartments), ${ }^{15}$ beginning in the most cellular area. Both the number of positive nuclei per HPF and the number of neoplastic cells intercepted by the microscope field diameter $(n)$ were recorded, the latter to estimate the number of neoplastic cells/HPF $[N=$ $\left.(n \pi / 4)^{2}\right] ;{ }^{13,16}$ results were expressed per 1000 cells, calculating average and standard deviation (SD) per compartment and patient. Tumours were graded by three independent observers (J.R., A.B. and S.J.D-C.); in cases of disagreement, tumours were reviewed simultaneously to achieve a consensus. Reproducibility data were not recorded. Dysplastic lesions were classified according to the World Health Organization/International Society of Urological Pathology system as low-grade dysplasia (LGUD) and carcinoma in situ (CIS). ${ }^{17}$

\section{TSG MICROSATELLITE ANALYSIS}

DNA was extracted from the most cellular areas of superficial and deep compartments, ${ }^{7,11,18-20}$ after microdissecting at least 100 cells $\left(\sim 0.4 \mathrm{~mm}^{2}\right.$, laser capture; Arturus, Mountain View, CA, USA) from two 20- $\mu$ m unstained paraffin sections/compartment (Figure 2). Appropriate controls (histologically normal urothelium, stroma from the lamina propria and smooth muscle) and quality assurance (sensitivity, specificity, positive and negative) were run for each test. ${ }^{21-23}$

DNA was extracted using a modified phenol-chloroform protocol, precipitated with ice-cold absolute ethanol and resuspended in $10 \mu \mathrm{l}$ of Tris- $\mathrm{HCl}$ buffer at $\mathrm{pH} 8.4 .^{23}$ DNA was then used for polymerase chain reaction (PCR) amplification of TSG intron microsatellites (Table 1). ${ }^{7,24}$ The tests were run in a Perkin-Elmer thermal cycler model 480 (Perkin-Elmer, Norwalk, CT, USA). The whole 10- $\mu$ PCR volume was electrophoresed onto $8 \%$ denaturing gradient polyacrylamide gels; dried gels were put inside developing cassettes containing one intensifying screen and preflashed films (Kodak XAR; Kodak Co., Rochester, NY, USA). ${ }^{7,24,25}$ The radiographs were developed using an automated processor Kodak-Omat 100 (Kodak Co.). 

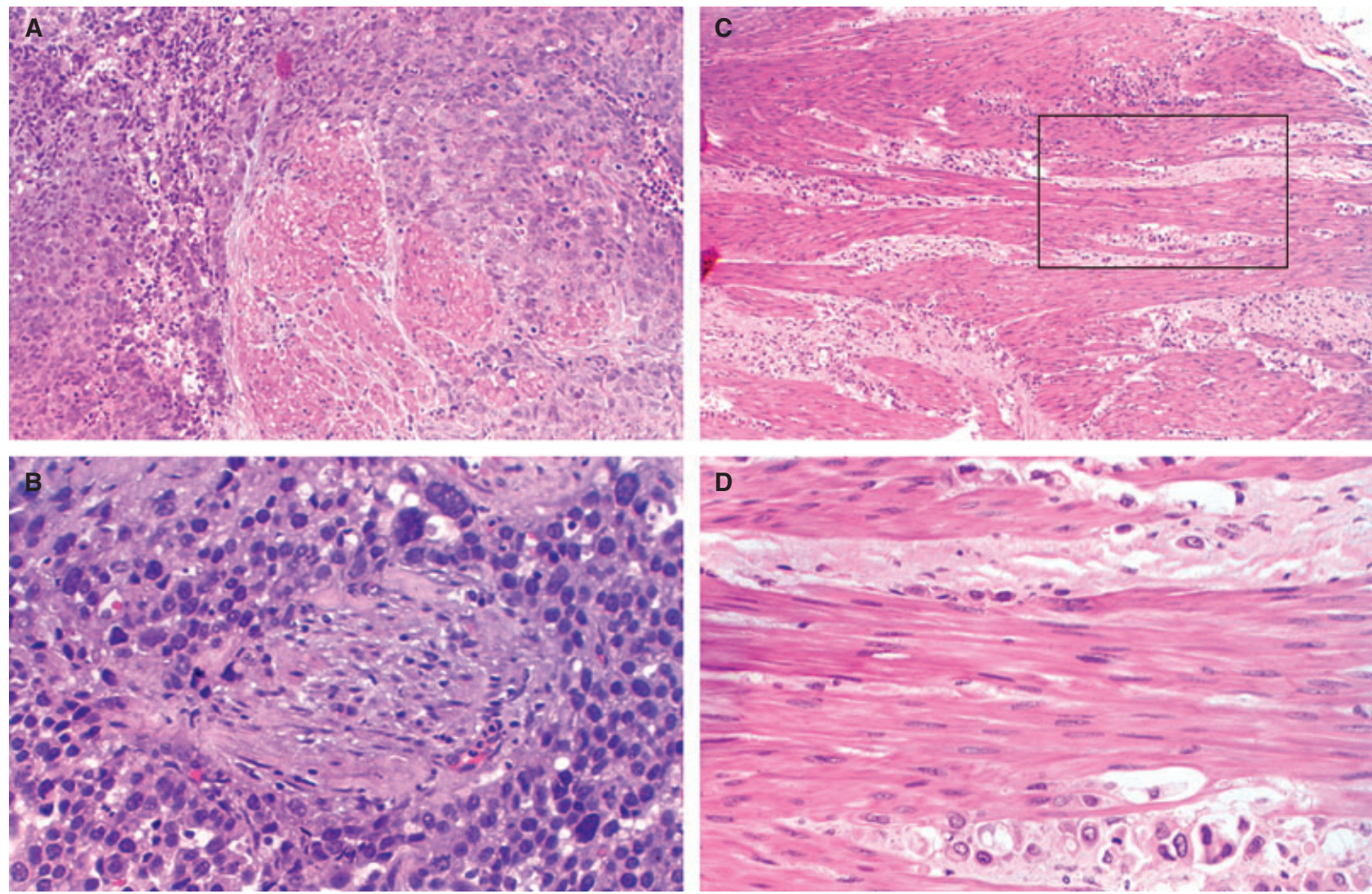

Figure 1. A,B, Nodular-trabecular urothelial carcinoma (UroC) shows sheets of neoplastic cells with minimal stromal reaction replacing the muscularis propria (haematoxylin and eosin). C,D, Infiltrative UroC shows small tumour nests/thin cords embedded in a prominent desmoplastic reaction, dissecting the smooth muscle fibres (haematoxylin and eosin).

Interpretation and inclusion criteria in each sample

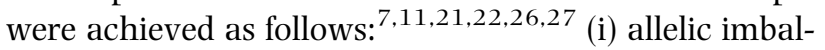
ance was densitometrically evaluated (EC model 910 optical densitometer; EC Apparatus Corp., St Petersburg, FL, USA). For evidence of loss of heterozygosity (LOH) only allele ratios $\geq 4: 1$ in any TSG were considered; otherwise retention of heterozygosity (ROH) was assigned. ${ }^{7,11}$ This ratio represents $80 \%$ of clonal cells in the sample and was used to increase the detection specificity; ${ }^{22,26,28}$ (ii) additional allele bands present in tumour samples but not in the corresponding controls were considered evidence of somatic single nucleotide polymorphism (SNP) by PCR/denaturing gradient gel electrophoresis. ${ }^{7,19,22,29}$

\section{DNA SEQUENCING}

All microsatellite marker extra bands were cut from gels and DNA was purified using a QIA quick gel extraction kit (Qiagen, Valencia, CA, USA). The amplified product was diluted 20-fold in Tris-ethylenediamine tetraaceticacid buffer and $1 \mu \mathrm{l}$ of the diluted reaction product was subjected to a second round of PCR amplification using the appropriate primers for 30 cycles under the above conditions. Normal and extra bands from tumour-derived samples were PCR amplified along with the corresponding controls using a high-fidelity polymerase, Platinum PFX (Life Technologies, Gaithersburg, MD, USA). PCR products were directly sequenced after purification (QIAquick PCR purification kit; Qiagen). All sequencing was performed on an ABI Prism 3700 automated DNA Analyser and the sequence data analysed using the program Sequencher (Gene Codes Corp., Ann Arbor, MI, USA), which reverses and complements the antisense strand. All mutations were confirmed by sequencing in both directions and indicated by an ' $\mathrm{N}$ ' in the sequencing chromatogram.

MLH1/MSH2 exons were completely sequenced in cases with microsatellite abnormalities in at least $40 \%$ of loci (high microsatellite instability) and/or complete loss of $\mathrm{mlh} 1 / \mathrm{msh} 2$ immunoreactivity, ${ }^{19,30}$ as well as in a representative sample from $\mathrm{mlh} 1 / \mathrm{msh} 2$ immunoreactive cases (20 UroC) used as controls. 


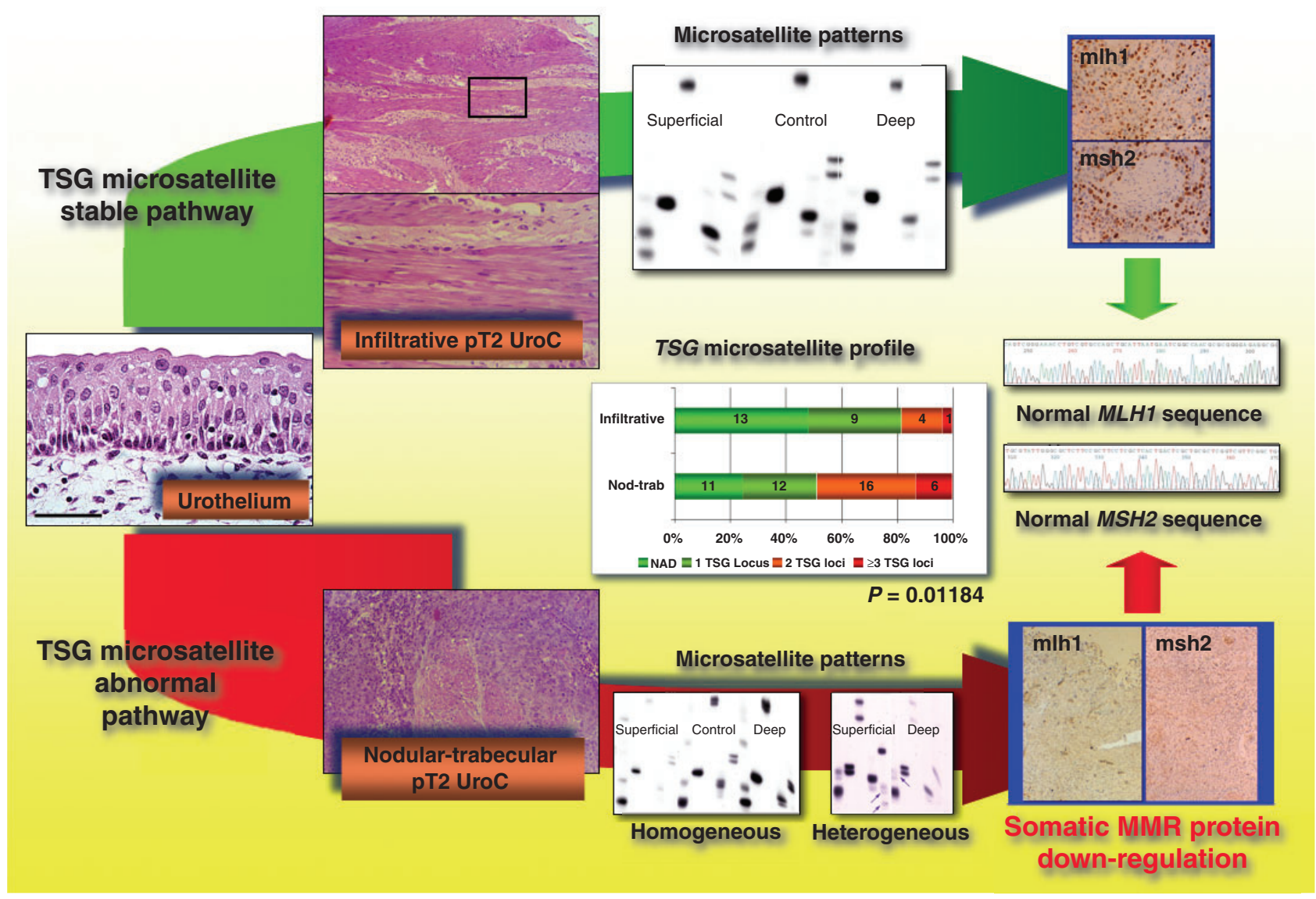

Figure 2. Microsatellite pathways in urothelial carcinomas (UroC). Microsatellite patterns. Muscle-invasive transitional cell carcinomas (UroC) with infiltrative infiltration pattern. Gels show no microsatellite abnormalities of tumour suppressor genes (TSG) in either superficial or deep compartments. Muscle-invasive UroC with nodular-trabecular infiltration pattern. Gels show concordant (homogeneous) and discordant (heterogeneous) microsatellite patterns of tumour suppressor genes in the superficial and deep compartments. TP53, Tumour protein p53 (two loci); RB1, retinoblastoma; WT1, Wilm's tumour 1; NF1, neurofibromatosis 1. TSG microsatellite profile. Number of TSG abnormalities detected in transitional cell carcinomas by infiltration patterns: infiltrative UroCs reveal two or more TSG loci with microsatellite abnormalities in $5 / 27$ cases $(18.5 \%)$, whereas nodular-trabecular UroCs show lower incidence of microsatellite lesions. Mismatch protein expression.

Nuclear mlh1 and msh2 expression is demonstrated in UroC in the microsatellite stable pathway and at least one of these proteins is absent (in particular mlh1) in UroC showing microsatellite instability. MLH1 and MSH2 exon sequencing. Normal sequence is demonstrated for these genes, regardless of the microsatellite pattern.

\section{IMMUNOHISTOCHEMiCAL DETECTION OF KI67, MLH1}

\section{AND MSH2}

Sections were mounted on positively charged slides (Superfrost Plus; Fisher Scientific, Fair Lawn, NJ, USA), baked at $60^{\circ} \mathrm{C}$ for $2 \mathrm{~h}$ and processed as described..$^{7,20,25}$ After routine dewaxing and rehydration, endogenous peroxidase quenching and antigen heat retrieval, the slides were transferred to a moist chamber. Non-specific binding was blocked with polyclonal horse serum and sections incubated with monoclonal primary antibodies (overnight, $4^{\circ} \mathrm{C}$ ): $2 \mu \mathrm{g} / \mathrm{ml} \mathrm{MIB-1}$ (Calbiochem, Cambridge, MA, USA), hMLH1 clones G168 728 and G168-15 (BD PharMingen, San Jose, CA, USA) and hMSH2 clone FE11 (Oncogene Research,
La Jolla, CA, USA). Sections were then serially incubated with biotinylated antimouse antibody and peroxidase-labelled avidin-biotin complex. The reaction was developed under microscopic control, using 3,3'diaminobenzidine tetrahydrochloride with $0.3 \% \mathrm{H}_{2} \mathrm{O}_{2}$ as chromogen (Sigma Co., St Louis, MO, USA) and the sections counterstained with haematoxylin. Positive (reactive lymph node) and negative (omitting the primary antibody) controls were run simultaneously.

\section{IN SITU END LABELLING OF FRAGMENTED DNA}

Extensive DNA fragmentation associated with apoptosis was detected by in situ end labelling (ISEL), as reported. ${ }^{10,13}$ After routine dewaxing and hydration, 


\begin{tabular}{|c|c|c|}
\hline Primers & Primer sequences & $\begin{array}{l}\text { Tandem repeat/ } \\
\text { PCR product }\end{array}$ \\
\hline $\operatorname{TP53}(1)-a^{*}$ & 5'-AGG GAT ACT ATT CAG CCC-3' & CA repeat/ \\
\hline $\operatorname{TP53}(1)-b^{*}$ & 5'-ACT GCC АCT ССT TGC CCC ATT C-3' & $103-135 \mathrm{bp}$ \\
\hline $\operatorname{TP53}(2)-a^{*}$ & 5'-GAA TCC GGG AGG AGG TTG-3' & AAAAT repeat/ \\
\hline $\operatorname{TP53}(2)-b^{*}$ & 5'-AAC AGC TCC TTT AAT GGC AG-3' & $140-175 \mathrm{bp}$ \\
\hline $\mathrm{RB} 1-\mathrm{a}^{*}$ & 5'-CTC CTC CCC TAC TTA CTT GT-3' & CTTT(T) repeat/ \\
\hline $\mathrm{RB} 1-\mathrm{b}^{*}$ & 5'-AAT TAA CAA GGT GTG GTG GTA CAC G-3' & 266-306 bp \\
\hline WT1-a* & 5'-AAT GAG ACT TAC TGG GTG AGG-3' & CA repeat/ \\
\hline WT1-b* & 5'-TTA CAC AGT AAT TTC AAG CAA CGG-3' & $\sim 144 \mathrm{bp}$ \\
\hline NF1-a* & 5'-CAG AGC AAG ACC CTG TCT-3' & CA repeat/ \\
\hline NF1-b* & 5'-CTC CTA ACA TTT ATT AAC CTT A-3' & $171-187 \mathrm{bp}$ \\
\hline
\end{tabular}

Table 1. Primer sequences and polymerase chain reaction (PCR) cycling conditions for the amplification of polymorphic DNA regions

All reactions were run in duplicate using $1.5 \mathrm{~mm}$ of $\mathrm{MgCl}_{2}$ and $1 \mu \mathrm{l}$ of template. A long denaturation (4 $\mathrm{min}$ ) and expansion (90 s) were used in the first three cycles for each set of primers.

${ }^{*}$ The polymorphic regions of tumour suppressor gene were amplified using $0.25 \mu \mathrm{M}$ of each primer, $50 \mu \mathrm{m}$ of each dNTP (Boehringer-Mannheim, Indianapolis, IN, USA) and internally labelled with $0.3 \mu \mathrm{Ci} \alpha^{32} \mathrm{P}-\mathrm{dCTP}(3000 \mathrm{Ci} / \mathrm{mmol}, 10 \mathrm{mCi} / \mathrm{mL}$ ) (New England Nucleotide, Boston MA, USA). The annealing temperature was $55^{\circ} \mathrm{C}$ for all primer sets (except NF1, for which it was $52^{\circ} \mathrm{C}$ ) and the number of cycles was experimentally optimized to 26 .

the sections were incubated in $2 \times$ standard saline citrate $\left(20 \mathrm{~min}\right.$ at $\left.80{ }^{\circ} \mathrm{C}\right)$ and digested with pronase $(500 \mu \mathrm{g} / \mathrm{ml}, 25 \mathrm{~min}$, room temperature) in a moist chamber.

DNA fragments were labelled on $5^{\prime}$-protuding termini by incubating the sections with the Klenow fragment of Escherichia coli DNA polymerase I $[20 \mathrm{U} / \mathrm{ml}$ in $50 \mathrm{mmol} / \mathrm{l}$ Tris-HCl, $\mathrm{pH} 7.5,10 \mathrm{mmol} / \mathrm{l}$ $\mathrm{MgCl}_{2}, 1 \mathrm{mmol} / \mathrm{l}$ dithiothreitol, $250 \mu \mathrm{g} / \mathrm{ml}$ bovine serum albumin (BSA), $5 \mu \mathrm{M}$ of each dATP, dCTP, dGTP, as well as $3.25 \mu \mathrm{mol} / \mathrm{l}$ dTTP and $1.75 \mu \mathrm{mol} / \mathrm{l}$ 11-digoxigenin-dUTP], at $37{ }^{\circ} \mathrm{C}$ in a moist chamber. The incorporated digoxigenin-dUMPs were immunoenzymatically detected using antidigoxigenin Fab fragments labelled with alkaline phosphatase $(7.5 \mathrm{U} / \mathrm{ml}$, in $100 \mathrm{mmol} / \mathrm{l}$ Tris-HCl, pH 7.6, $150 \mathrm{mmol} / \mathrm{l} \mathrm{NaCl}, 1 \%$ BSA) for $4 \mathrm{~h}$ at room temperature. The reactions were developed with the mixture nitroblue tetrazolium-X phosphate in $100 \mathrm{mmol} / \mathrm{l}$ Tris-HCl (pH 9.5), 100 $\mathrm{mmol} / \mathrm{l} \mathrm{NaCl}$, $50 \mathrm{mmol} / \mathrm{l} \mathrm{MgCl}_{2}$ under microscopic control. Appropriate controls were simultaneously run, including positive (reactive lymph node), negative (same conditions omitting DNA polymerase I) and enzymatic (DNase I digestion before the end labelling) controls. The enzymatic controls were used to establish the positivity threshold reliably in each sample.
NUCLEAR DNA QUANTIFICATION BY SLIDE CYTOMETRY

Feulgen-stained sections were used for DNA quantification. ${ }^{31}$ Densitometric evaluation was performed with the cell analysis system model 200 and quantitative DNA analysis software package (Becton Dickinson, San Jose, CA, USA). At least 300 complete, non-overlapping and focused nuclei (or the whole lesion if smaller) were measured in every case, beginning in the most cellular area until completion in consecutive HPFs.

External staining calibration was carried out with complete rat hepatocytes (Becton Dickinson; one slide per staining holder) to normalize the internal controls (lymphocytes and histologically normal urothelial cells present in the same tissue section), used for setting the $G_{0} / G_{1}$ cell limits and calculating the DNA index of each $\mathrm{G}_{0} / \mathrm{G}_{1}$ peak (> $10 \%$ of measured cells with evidence of $\mathrm{G}_{2}+\mathrm{M}$ cells). ${ }^{32}$ Proliferation rate $(\mathrm{PR}=$ $\mathrm{S}+\mathrm{G}_{2}+\mathrm{M}$-phases fraction) was calculated from the DNA histogram by subtracting the number of cells within $\mathrm{G}_{0} / \mathrm{G}_{1}$ limits from the total number of measured cells and expressed as a percentage. ${ }^{31,32}$

The scatter analysis of nuclear area and DNA content allowed apoptotic cell identification in each cell cycle phase (low nuclear area for a given DNA 
content) ${ }^{33}$ and was coupled with ISEL to identify apoptotic DNA fragmentation (see above). External diploid controls were used to determine DNA indices (lymphocytes from reactive lymph nodes) and to standardize the nuclear area/DNA content analysis (normal transitional cells). ${ }^{33}$

\section{QUANTIFICATION OF POSITIVE NUCLEI AND}

STATISTICAL ANALYSIS

At least $50 \mathrm{HPF}\left(7.6 \mathrm{~mm}^{2}\right)$ were screened in each pathological group, beginning in the most cellular area. The number of positive nuclei was expressed per HPF and per 1000 tumour cells, and the average and SD calculated in each pathological condition and patient as described. ${ }^{11,13,16}$ The positivity threshold was experimentally established from the positive control in each staining batch. Only nuclei with staining features similar to those of their corresponding positive control were considered positive for any marker.

All variables were compared by infiltration pattern (nodular-trabecular versus infiltrative) in deep compartments and the cancer-specific survival assessed (Kaplan-Meier analysis). Qualitative variables were statistically tested using Fisher's exact tests, whereas quantitative variables were compared using Student $t$-tests and analysis of variance. Differences were considered significant if $P<0.05$ in two-tailed distributions.

\section{Results}

Patients aged $59-78$ years $(64.3 \pm 8.7)$ complained of painless haematuria (72 cases, $100 \%$ ), irritative symptoms (15 cases, $20.8 \%$ ), with no differences between infiltration patterns. Tumours revealed a nodulartrabecular infiltration pattern in 45 cases $(63 \%$, Figure 2) and infiltrative in 27 cases (37\%, Figure 2), aneuploid nuclear DNA content in 59 cases $(82 \%$, always concordant in superficial and deep compartments) and high-grade in 62 cases (86\%). LGUD was found in 18 cases and CIS in 12, both lesions being coexistent in five patients. LGUD was mainly associated with infiltrative UroC, whereas CIS was associated with nodular-trabecular UroC only $(P=0.0053)$ (Table 2$)$. No dysplastic changes were found in 47 UroCs $(65 \%)$.

Nodular-trabecular UroCs were more frequently aneuploid and high-grade than infiltrative UroCs (Table 2). The number of diploid (10 cases) and lowgrade (eight cases) UroCs precluded any statistical comparisons of these features. The median survival was significantly longer for nodular-trabecular than for infiltrative UroCs (Figure 3, $P=0.0445$ ). Nodular-
Table 2. Muscle-invasive urothelial carcinomas by infiltration patterns: morphological and DNA cytometry features

\begin{tabular}{lccc}
\hline & $\begin{array}{l}\text { Nodular- } \\
\text { trabecular } \\
\text { pT2a/ } \\
\text { b UroC }\end{array}$ & $\begin{array}{l}\text { Infiltrative } \\
\text { pT Uro } \\
\text { b Uroc }\end{array}$ & $\begin{array}{l}\text { Significance, } \\
P\end{array}$ \\
\hline $\begin{array}{l}\text { Tumour grade } \\
\text { Low }\end{array}$ & 3 & 5 & 0.0329 \\
\hline High & 46 & 16 & \\
\hline $\begin{array}{l}\text { Nuclear grade } \\
\text { Low }\end{array}$ & 3 & 5 & 0.0329 \\
\hline HIgh & 46 & 16 & 0.0004 \\
\hline $\begin{array}{l}\text { Urothelial dysplasia } \\
\text { No dysplasia }\end{array}$ & 30 & 17 & \\
\hline Low-grade & 3 & 10 & \\
\hline CIS & 12 & 0 & \\
\hline DNA ploidy & 1 & 9 & \\
\hline Diploid & 48 & 11 & \\
\hline Aneuploid & & & \\
\hline
\end{tabular}

CIS, Carcinoma in situ.

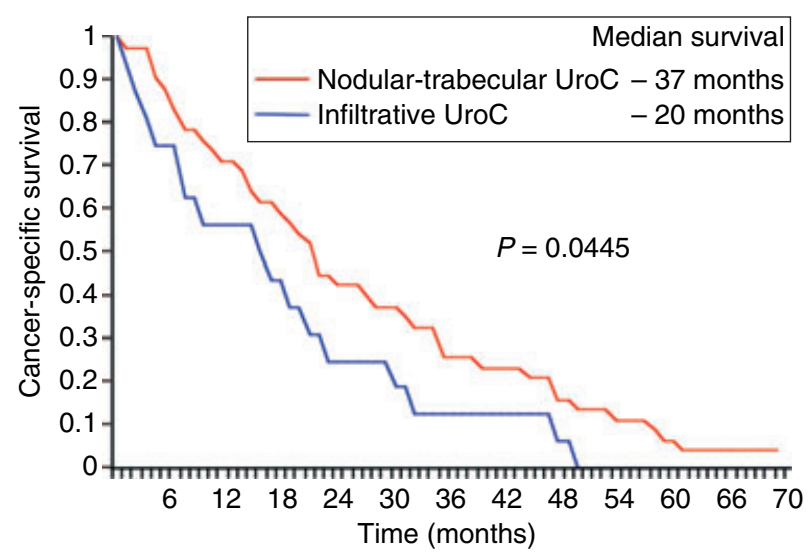

Figure 3. Cancer-specific survival in patients with muscle-invasive transitional cell carcinomas (UroC) by infiltration pattern (nodulartrabecular versus infiltrative).

trabecular UroCs and superficial compartments showed significantly higher values for both proliferation and apoptosis markers (Table 3).

Nodular-trabecular UroCs revealed more abnormal loci than infiltrative UroCs (Figure 2, $P=0.0001$ ). Discordant genetic patterns by tumour compartments were observed in only three infiltrative UroCs, precluding any statistical assessment, but all showed nuclear 
Table 3. Kinetic features of muscle-invasive urothelial carcinomas (UroC) by infiltration patterns (nodular-trabecular versus infiltrative) and tumour compartments (superficial versus deep)

\begin{tabular}{|c|c|c|c|c|c|}
\hline & \multicolumn{2}{|c|}{ Nodular-trabecular pT2a/b UroC } & \multicolumn{2}{|c|}{ Infiltrative $\mathrm{pT} 2 \mathrm{a} / \mathrm{b}$ UroC } & \multirow{2}{*}{$\begin{array}{l}\text { Significance, } \\
P\end{array}$} \\
\hline & Superficial & Deep & Superficial & Deep & \\
\hline MF counting & $9.0 \pm 5.1$ & $4.1 \pm 3.1$ & $5.9 \pm 3.5$ & $2.0 \pm 1.8$ & 0.012 \\
\hline Ki67 index & $28.25 \pm 6.01$ & $13.09 \pm 4.89$ & $25.12 \pm 6.22$ & $10.76 \pm 4.28$ & 0.005 \\
\hline Proliferation rate & $33.74 \pm 7.60$ & $19.69 \pm 6.15$ & $26.46 \pm 8.36$ & $14.57 \pm 4.58$ & 0.009 \\
\hline ISEL index & $21.1 \pm 22.5$ & $19.3 \pm 22.9$ & $11.0 \pm 4.6$ & $17.2 \pm 15.4$ & 0.048 \\
\hline
\end{tabular}

MF, Mitotic figure; ISEL, in situ end labelling.

TP53 expression and more $\mathrm{LOH} / \mathrm{SNP}(\mathrm{s})$ in the deep compartment (WT1 LOH/SNP in two and NF1 $\mathrm{LOH} / \mathrm{SNP}$ in one). The distribution of $\mathrm{LOH} / \mathrm{SNP}(\mathrm{s})$ was also significantly different according to the infiltration pattern: nodular-trabecular UroC revealed a higher proportion of abnormal RB1 $(P=0.0003)$ and NF1 $(P=0.0023)$ loci (Figure 4). Considering all genetic lesions equally important, the normal tissue ROH probability was $P_{\mathrm{ROH}}=1-P_{\mathrm{LOH}}=1-0.2=$ 0.8 for a given marker, ${ }^{34-36} 0.8^{5}$ for five markers and $\left(0.8^{5}\right)^{2}$ for concordant superficial and deep compartments results of those five markers. ${ }^{7,20}$ It will result in $\left[\left(0.8^{5}\right)^{2}\right]^{12}$ for 12 UroC and $\left[\left(0.8^{5}\right)^{2}\right]^{12} \times 0.38^{12}=$ $2.85 \times 10^{17}$ if they are infiltrative UroC $(38 \%$ of muscle-invasive UroC).

At least one MMR protein (always including mlh1) was not expressed in nodular-trabecular UroC with two or more abnormal TSG loci, but both MMR proteins were present in tumours with less than two abnormal TSG loci. MLH1 and MSH2 exon sequencing revealed no mutations, regardless of the number of abnormal TSG loci (Figure 2).

\section{Discussion}

Somatic down-regulation of MMR proteins in nodulartrabecular muscle-invasive UroC results in microsatellite abnormalities characterized by deletion/SNP(s) in RB1 and NF1, which correlates with higher cellular turnover and longer survival for these patients.

Infiltrative UroC showed a low incidence of TSG LOH/SNP, whereas nodular-trabecular UroC accumulated TSG alterations (Figure 2). Technical reasons were excluded. The sensitivity threshold of our optimized protocol was $1 \%$ for positive detection, ${ }^{7,11,22,26}$ which applied to $100+$ cell samples would result in false-negative results for DNA samples smaller than one cell equivalent. This is probably clinically irrelevant and frequently related to contamination. Repea- ted microdissection under microscopic control with the same results and multiple sampling excluded any significant contamination with normal tissue. ${ }^{1,20,22,26,28}$ Although TSG LOH/SNP(s) can be present outside of the screened introns, the importance of these results is still supported by two facts: the low probability of it as a random finding and its significant association with infiltrative UroC and shorter survival.

MMR protein down-regulation and abnormal TSG microsatellites characterized nodular-trabecular UroC with CIS (12 cases, $P=0.0053)$ and deep UroC compartments, ${ }^{25,37,38}$ correlating with lack of mlh1/ msh2 immunoexpression and normal gene sequences. MMR proteins normally identify and correct mismatched DNA sequences that can occur during DNA replication. ${ }^{30}$ MMR protein down-regulation in deep compartments and nodular-trabecular UroC would contribute to: (i) lower DNA indices and decreased prevalence of aneuploid cell lines detected in neoplasms with microsatellite abnormalities, ${ }^{39,40}$ which frequently show diploid DNA content, ${ }^{25,37,41}$ and loss of the physiological cell kinetic correlations in deep compartments; ${ }^{37}$ and (ii) tumour cell heterogeneity, genetic instability and biological progression, which must be studied with several samples of sufficient size from each tumour. ${ }^{18,21,22,26}$ Because of intratumoral heterogeneity, at least two samples from each tumour should be screened, preferably from superficial and deep compartments to allow for topographical heterogeneity. ${ }^{18,21,22,26,42,43}$ MMR gene inactivation (by either mutation or protein down-regulation) leading to mutation accumulation (as proven in this series in TSG) and molecular progression, ${ }^{19,22,44,45}$ not necessarily independent of chromosomal instability, may coexist in a given neoplasm and show a significant degree of overlap. ${ }^{46}$

Nodular-trabecular UroC revealed significantly higher proliferation and apoptosis than infiltrative UroC, which would contribute to a relative sensitivity to 
A

MS profile in $\mathrm{pT} 2$ UroC by infiltration pattern

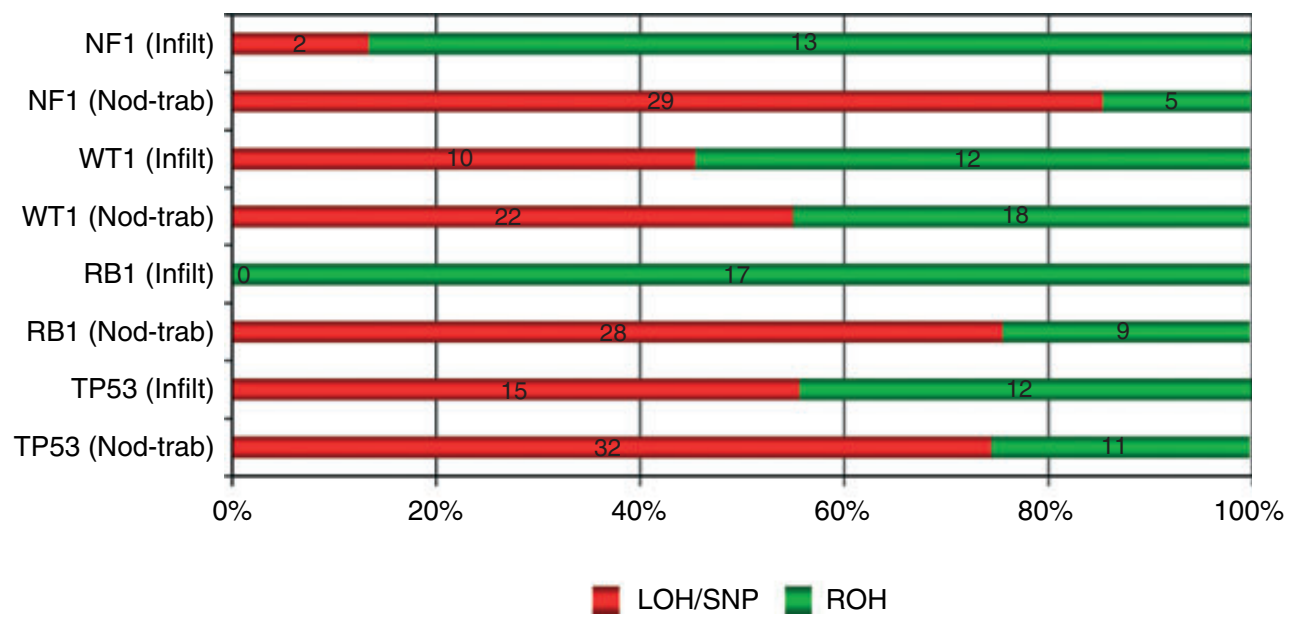

$\square$ Concordant $\square$ Discordant
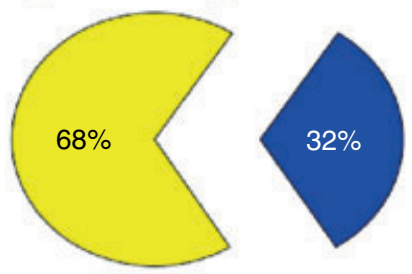

B UroC with topographically homogeneous MS pattern

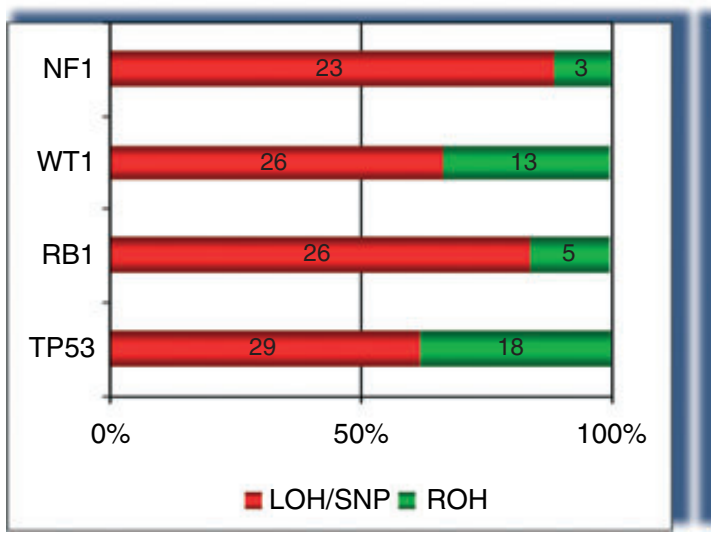

C

UroC with topographically heterogeneous MS pattern

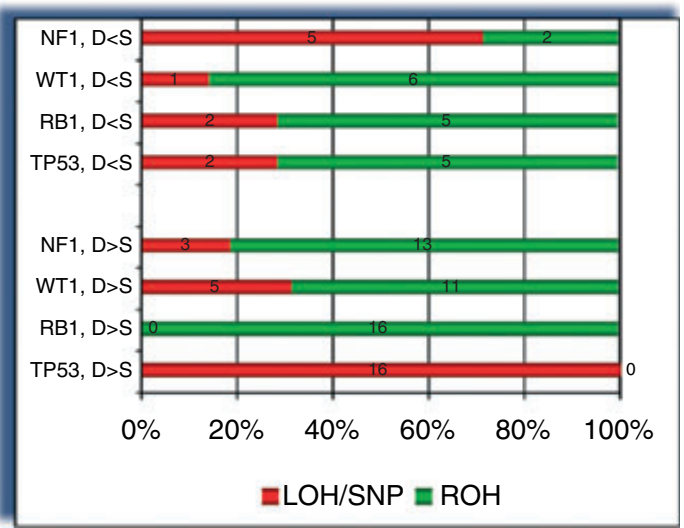

Figure 4. Distribution of microsatellite abnormalities in each tumour suppressor gene (TSG) in urothelial carcinoma (UroC) by infiltration patterns (A, solid-nodular versus infiltrative). NF1 loss of heterozygosity (LOH)/single nucleotide polymorphism(s) (SNP) was more frequently found in superficial compartments and TP53 LOH/SNP(s) in deep compartments, although only TP53 showed significant differences by tumour compartments $(P=0.0213)$. UroC showed topographically concordant microsatellite (MS) patterns in 49 cases $(68 \%$, B) and discordant in 23 cases $(32 \%$, C), TSG LOH / SNP average being higher in the former; the variability, however, was higher in the latter group. Significant differences were demonstrated only for the comparisons between UroCs with more MS abnormalities in the deep compartment (15 cases) and (A) UroCs with no topographical heterogeneity (49 cases; TP53, $P=0.0322 ; R B 1, P=0.0001$; and NF1, $P=0.0017$ ), and (B) UroCs with more LOH/SNP(s) in the superficial compartment (eight cases; TP53, $P=0.0363$; and NF1, $P=0.0450$ ) (c). Comparison between UroCs with no topographical heterogeneity and UroCs with more LOH/SNP(s) in the superficial compartment revealed no statistically significant differences. TP53, Tumour protein p53; RB1, retinoblastoma; WT1, Wilm's tumour 1; NF1, neurofibromatosis 1; ROH, retention of heterozygosity.

conventional treatment and eventually longer survival (Figure 3), as reported for neoplasms with TSG microsatellite abnormalities. ${ }^{30}$ Nodular-trabecular UroC more frequently revealed high tumour/nuclear grade, aneuploid DNA content (Table 2) and higher proliferation and apoptotic indices. Lack of MMR protein 
expression in these neoplasms would lead to accumulation of genetic alterations, which, reaching lethal limits, results in increased apoptosis and, eventually, a better response to therapy. ${ }^{19,30}$ The aneuploid DNA content and proliferation rate are directly related to tumour/nuclear grade, ${ }^{7,20,25}$ both predominating in nodular-trabecular UroC; however, the up-regulated apoptosis in this subgroup of muscle-invasive UroC would account for the paradoxically better survival of these patients.

Nodular-trabecular UroCs were significantly associated with topographical heterogeneity, RB1 and NF1 $\mathrm{LOH} / \mathrm{SNP}(\mathrm{s})$ and higher cellular turnover. ${ }^{7,8,25}$ It has been postulated that aberrant pRB1 expression deregulates $G_{1}$ cell cycle checkpoint and provides tumour cells with increased proliferation and a reduced response to programmed cell death. ${ }^{47}$ However, high levels of pRB1 expression may reflect a dysfunctional RB1 pathway and do not necessarily reflect the tumour suppressor effects of the protein. ${ }^{48}$ Nevertheless, the absence of an inhibitory effect of functional pRB1 leads to increased proliferation in nodular-trabecular UroC. The presence of NF1 LOH/SNP was especially documented in the superficial compartment of nodulartrabecular UroC. The NF1 gene product has an inhibitory effect on RAS, whose protein is highly expressed in immature and proliferating cells, and the lack of its inhibitory effect will favour increased cell proliferation, ${ }^{8,25,49}$ also confirmed by decreased NF1 mRNA and protein levels in high-grade UroC, suggesting an NF1 role in bladder carcinogenesis. ${ }^{7,50}$ These findings are an expression of the disturbed tumour kinetics, ${ }^{10,11,13}$ which result in high cellular turnover and the preferentially expansive nature of nodulartrabecular UroC.

In conclusion, nodular-trabecular muscle-invasive UroC reveals greater proliferation and a higher incidence of RB1 and NF1 LOH/SNP(s) than infiltrative UroC, together with longer survival. A significantly low incidence of TSG LOH/SNP(s) suggests a microsatellite stable pathway for infiltrative UroC.

\section{Acknowledgements}

Presented in part as abstract at the Meeting of the Pathological Society of Great Britain and Ireland, London, UK, 2000 and USCAP Meetings in New Orleans, Louisiana, 2000 and in San Antonio, Texas, 2005.

\section{References}

1. Cohen MB, Waldman FM, Carroll PR, Kerschmann R, Chew K, Mayall BH. Comparison of five histopathologic methods to assess cellular proliferation in transitional cell carcinoma of the urinary bladder. Hum. Pathol. 1993; 24; 772-778.

2. Hierro Martin I, Alvarez Perez M, Blanes Berenguel A et al. Contribucion a la categorizacion de los CCT de vejiga, sistematizacion de la gradacion y utilidad de la ploidia de ADN. Actas Urol. Esp. 1999; 23; 489-496.

3. Jimenez RE, Gheiler E, Oskanian $\mathrm{P}$ et al. Grading the invasive component of urothelial carcinoma of the bladder and its relationship with progression-free survival. Am. J. Surg. Pathol. 2000; 24; 980-987.

4. Smits G, Schaafsma E, Kiemeney L, Caris C, Debruyne F, Witjes JA. Microstaging of pT1 transitional cell carcinoma of the bladder: identification of subgroups with distinct risks of progression. Urology 1998; 52; 1009-1013; discussion 10131004.

5. Younes M, Sussman J, True LD. The usefulness of the level of the muscularis mucosae in the staging of invasive transitional cell carcinoma of the urinary bladder. Cancer 1990; 66; 543-548.

6. Hermann GG, Horn T, Steven K. The influence of the level of lamina propria invasion and the prevalence of p53 nuclear accumulation on survival in stage $\mathrm{T} 1$ transitional cell bladder cancer. J. Urol. 1998; 159; 91-94.

7. Diaz-Cano SJ, Blanes A, Rubio J, Matilla A, Wolfe HJ. Molecular evolution and intratumor heterogeneity by topographic compartments in muscle-invasive transitional cell carcinoma of the urinary bladder. Lab. Invest. 2000; 80; 279-289.

8. Baithun SI, Naase M, Blanes A, Diaz-Cano SJ. Molecular and kinetic features of transitional cell carcinomas of the bladder. Biological and clinical implications. Virchows Arch. 2001; 438; 289-297.

9. Pozo L, Camacho F, Rios-Martin JJ, Diaz-Cano SJ. Cell proliferation in skin tumors with ductal differentiation: patterns and diagnostic applications. J. Cutan. Pathol. 2000; 27; 292-297.

10. Diaz-Cano SJ, Garcia-Moliner M, Carney W, Wolfe HJ. Bcl-2 expression and DNA fragmentation in breast carcinoma, pathologic and steroid hormone receptors correlates. Diagn. Mol. Pathol. 1997; 6; 199-208.

11. Diaz-Cano SJ, de Miguel M, Blanes A, Tashjian R, Galera H, Wolfe HJ. Clonality as expression of distinctive cell kinetic patterns in nodular hyperplasias and adenomas of the adrenal cortex. Am. J. Pathol. 2000; 156; 311-319.

12. Salomon RN, Diaz-Cano S. Introduction to apoptosis. Diagn. Mol. Pathol. 1995; 4; 235-238.

13. Koch M, de Miguel M, Höfler H, Diaz-Cano SJ. Kinetic profiles of intraepithelial and invasive prostatic neoplasias: the key role of downregulated apoptosis in tumor progression. Virchows Arch. 2000; 436; 413-420.

14. Ro JY, Ayala AG, el-Naggar A. Muscularis mucosa of urinary bladder. Importance for staging and treatment. Am. J. Surg. Pathol. 1987; 11; 668-673.

15. van Diest PJ, Baak JP, Matze-Cok P et al. Reproducibility of mitosis counting in 2,469 breast cancer specimens: results from the Multicenter Morphometric Mammary Carcinoma Project. Hum. Pathol. 1992; 23; 603-607.

16. Harjacek M, Diaz-Cano S, Alman BA et al. Prominent expression of mRNA for proinflammatory cytokines in synovium in patients with juvenile rheumatoid arthritis or chronic lyme arthritis. J. Rheumatol. 2000; 27; 497-503.

17. Epstein JI, Amin MB, Reuter VR, Mostofi FK. The World Health Organization/International Society of Urological Pathology consensus classification of urothelial (transitional cell) neoplasms of the urinary bladder. Bladder Consensus Conference Committee. Am. J. Surg. Pathol. 1998; 22; 1435-1448. 
18. Blanes A, Diaz-Cano SJ. DNA and kinetic heterogeneity during the clonal evolution of adrenocortical proliferative lesions. Hum. Pathol. 2006; 37; 1295-1303.

19. Blanes A, Sanchez-Carrillo JJ, Diaz-Cano SJ. Topographic molecular profile of pheochromocytomas: role of somatic downregulation of mismatch repair. J. Clin. Endocrinol. Metab. 2006; 91; 1150-1158.

20. Diaz-Cano SJ, de Miguel M, Blanes A, Tashjian R, Galera H, Wolfe $\mathrm{HJ}$. Clonal patterns in phaechromocytomas and MEN-2A adrenal medullary hyperplasias: histologic and kinetic correlates. J. Pathol. 2000; 192; 221-228.

21. Diaz-Cano SJ. Are PCR artifacts in microdissected samples preventable? Hum. Pathol. 2001; 32; 1415.

22. Diaz-Cano SJ, Blanes A, Wolfe HJ. PCR techniques for clonality assays. Diagn. Mol. Pathol. 2001; 10; 24-33.

23. Diaz-Cano SJ, Brady SP. DNA extraction from formalin-fixed, paraffin-embedded tissues: protein digestion as a limiting step for retrieval of high-quality DNA. Diagn. Mol. Pathol. 1997; 6; 342-346.

24. Cawkwell L, Lewis FA, Quirke P. Frequency of allele loss of DCC, p53, RBI, WT1, NF1, NM23 and APC/MCC in colorectal cancer assayed by fluorescent multiplex polymerase chain reaction. Br. J. Cancer 1994; 70; 813-818.

25. Blanes A, Rubio J, Martinez A, Wolfe HJ, Diaz-Cano SJ. Kinetic profiles by topographic compartments in muscle-invasive transitional cell carcinomas of the bladder: role of TP53 and NF1 genes. Am. J. Clin. Pathol. 2002; 118; 93-100.

26. Diaz-Cano SJ. Designing a molecular analysis of clonality in tumours. J. Pathol. 2000; 191; 343-344.

27. Mutter GL, Boynton KA. X chromosome inactivation in the normal female genital tract: implications for identification of neoplasia. Cancer Res. 1995; 55; 5080-5084.

28. Diaz-Cano SJ. Clonality studies in the analysis of adrenal medullary proliferations. Application principles and limitations. Endocr. Pathol. 1998; 9; 301-316.

29. Diaz-Cano SJ, de Miguel M, Blanes A, Tashjian R, Wolfe HJ. Germline RET 634 mutation positive MEN 2A-related C-cell hyperplasias have genetic features consistent with intraepithelial neoplasia. J. Clin. Endocrinol. Metab. 2001; 86; 3948-3957.

30. Blanes A, Diaz-Cano SJ. Complementary analysis of microsatellite tumor profile and mismatch repair defects in colorectal carcinomas. World J. Gastroenterol. 2006; 12; 5932-5940.

31. Bibbo M, Bartels PH, Dytch HE, Wied GL. Cell image analysis. In Bibbo M ed. Comprehensive cytopathology. Philadelphia: Saunders Co., 1991; 965-983.

32. Dressler LG. Controls, standards, and histogram interpretation in DNA flow cytometry. Meth. Cell. Biol. 1990; 33; 157-171.

33. Sherwood SW, Schimke RT. Cell cycle analysis of apoptosis using flow cytometry. Meth. Cell Biol. 1995; 46; 77-97.

34. Chen LC, Kurisu W, Ljung BM, Goldman ES, Moore DI, Smith HS. Heterogeneity for allelic loss in human breast cancer. J. Natl Cancer Inst. 1992; 84; 506-510.

35. Deng G, Lu Y, Zlotnikov G, Thor AD, Smith HS. Loss of heterozygosity in normal tissue adjacent to breast carcinomas. Science 1996; 274; 2057-2059.
36. Diaz-Cano SJ, Wolfe HJ. Clonality in Kaposi's sarcoma [letter; comment]. N. Engl. J. Med. 1997; 337; 571-572.

37. Blanes A, Jimenez-Martin JJ, Miranda MT, Diaz-Cano SJ. Absence of the physiologic cellular kinetic balance and down-regulation of $\mathrm{mlh} 1 / \mathrm{msh} 2$ characterize deep topographic compartments of colo-rectal adenocarcinomas. Lab. Invest. 2003; 83; 114A-115A (Abstract).

38. Jimenez JJ, Blanes A, Diaz-Cano SJ. Microsatellite instability in colon cancer. N. Engl. J. Med. 2003; 349; 1774-1776; author reply $1774-1776$.

39. Liang JT, Chang KJ, Chen JC et al. Clinicopathologic and carcinogenetic appraisal of DNA replication error in sporadic T3NOMO stage colorectal cancer after curative resection. Hepatogastroenterology 1999; 46; 883-890.

40. Thibodeau SN, French AJ, Cunningham JM et al. Microsatellite instability in colorectal cancer: different mutator phenotypes and the principal involvement of hMLH1. Cancer Res. 1998; 58; $1713-1718$.

41. Jimenez-Martin JJ, Miranda MT, Blanes A, Diaz-Cano SJ. Expression of $\mathrm{mlh} 1 / \mathrm{msh} 2$ in colo-rectal adenocarcinomas: SAGE/ microarray profile and tumor phenotype. Lab. Invest. 2003; 83; 296A (Abstract).

42. Chapusot C, Martin L, Bouvier AM et al. Microsatellite instability and intratumoural heterogeneity in 100 rightsided sporadic colon carcinomas. Br. J. Cancer 2002; 87; 400-404.

43. Chapusot C, Martin L, Mungra N et al. Sporadic colorectal cancers with defective mismatch repair display a number of specific morphological characteristics: relationship between the expression of hMLH1 and hMSH2 proteins and clinicopathological features of 273 adenocarcinomas. Histopathology 2003; 43; 40-47.

44. Duval A, Hamelin R. Mutations at coding repeat sequences in mismatch repair-deficient human cancers: toward a new concept of target genes for instability. Cancer Res. 2002; 62; 2447-2454.

45. Peltomaki P. DNA mismatch repair and cancer. Mutat. Res. 2001; 488; 77-85.

46. Goel A, Arnold CN, Niedzwiecki D et al. Characterization of sporadic colon cancer by patterns of genomic instability. Cancer Res. 2003; 63; 1608-1614.

47. Cordon-Cardo C, Zhang ZF, Dalbagni G et al. Cooperative effects of $\mathrm{p} 53$ and pRB alterations in primary superficial bladder tumors. Cancer Res. 1997; 57; 1217-1221.

48. Cote RJ, Dunn MD, Chatterjee SJ et al. Elevated and absent $\mathrm{pRb}$ expression is associated with bladder cancer progression and has cooperative effects with p53. Cancer Res. 1998; 58; 10901094.

49. Furth ME, Aldrich TH, Cordon-Cardo C. Expression of ras protooncogene proteins in normal human tissues. Oncogene 1987; 1; 47-58.

50. Aaltonen V, Bostrom PJ, Soderstrom KO et al. Urinary bladder transitional cell carcinogenesis is associated with down-regulation of NF1 tumor suppressor gene in vivo and in vitro. Am. J. Pathol. 1999; 154; 755-765. 